\title{
Overexpression of close homolog of L1 enhances the chemosensitivity of lung cancer cells via inhibition of the Akt pathway
}

\author{
XIANGDAO CAI ${ }^{1}$, BANG HU $^{1}$, SHENG LIU ${ }^{1}$, MAOLIN LIU $^{1}$, YUNHE HUANG ${ }^{1}$, PENG LEI ${ }^{1}$, \\ ZHI ZHANG ${ }^{1}$, ZHIWEI HE ${ }^{1}$, LINQUAN ZHANG ${ }^{1}$ and RIMAO HUANG ${ }^{1,2}$ \\ ${ }^{1}$ Department of Cardiothoracic Surgery, Xiangya Changde Hospital, Changde, Hunan 415000; \\ ${ }^{2}$ Department of Cardiovascular Surgery, Xiangya Hospital, Central South University, Changsha, Hunan 418008, P.R. China
}

Received October 3, 2019; Accepted May 27, 2020

DOI: $10.3892 / \mathrm{ol} .2020 .11972$

\begin{abstract}
Drug resistance leads to tumor relapse and further progression during chemotherapy in lung cancer. Close homolog of L1 (CHL1) has been identified as a tumor suppressor in most malignancies. However, to the best of our knowledge, whether CHL1 mediates chemoresistance remains unknown. The present study observed that CHL1 was significantly downregulated in cisplatin (DDP)-resistant cells (A549/DDP) and paclitaxel (PTX)-resistant cells (A549/PTX) compared with A549 cells. When treated with or without DDP and PTX, silencing of CHL1 in A549 cells promoted the cell survival rate and clone formation, and decreased apoptosis. Whereas overexpression of CHL1 in A549/DDP and A549/PTX cells impeded the cell survival and clone formation and promoted apoptosis. Additionally, CHL1 overexpression enhanced the chemosensitivity of A549/DDP cells to DDP in vivo. Notably, the chemoresistance induced by CHL1 depletion was reversed by the Akt inhibitor SC66 in A549 cells. The results of the present study demonstrated that CHL1 enhanced sensitivity of lung cancer cells by suppressing the Akt pathway, which suggested that CHL1 may be a potential target for overcoming chemoresistance in lung cancer.
\end{abstract}

\section{Introduction}

Lung cancer is the most common human malignancy, accounting for $21.7 \%$ of all cancer-associated deaths worldwide during 2015 (1). In addition, its morbidity and mortality rank the highest among all malignant tumor types worldwide (2). According to the differentiation degree and morphological

Correspondence to: Dr Rimao Huang, Department of Cardiothoracic Surgery, Xiangya Changde Hospital, Moon Avenue, West of Langzhou North Road, Changde, Hunan 415000, P.R. China E-mail: xyhuangrm@163.com

Key words: lung cancer, close homolog of 1, cisplatin, paclitaxel, chemosensitivity characteristics of cancer cells, lung cancer can be roughly classified into non-small-cell lung cancer (NSCLC) and small-cell lung cancer (3). Among patients with lung cancer, nearly $80 \%$ are diagnosed as NSCLC, which manifests with earlier diffusion and metastasis (4). Currently, resection, chemotherapy, radiotherapy and targeted therapy are the primary treatments for lung cancer (5). For patients with advanced NSCLC or those who are clinically incapacitated for surgery, chemotherapy is a remarkably important treatment (6). Cisplatin (DDP) is widely applied in the treatment of several malignancies, and it exhibits a broad spectrum of antitumor effects by inducing DNA damage and hindering DNA damage repair (7). Paclitaxel (PTX), another commonly used chemotherapeutic agent in the clinic, targets the microtubule cytoskeleton and impedes cell division $(8,9)$. The majority of patients have a good initial response to chemotherapy agents; however, subsequent relapse is common and largely due to the emergence of drug resistance (10). Thus, chemoresistance is considered one of the main factors of poor prognosis in patients with advanced NSCLC (6). Therefore, there is an urgent need to investigate the target and mechanism of chemoresistance in NSCLC.

Close homolog of L1 (CHL1) is a member of the L1 family of nerve cell adhesion molecules and is located on the $3 q 26$ locus (11). As a nerve cell adhesion molecule, CHL1 serves an important role in the development, regeneration and plasticity of the nervous system (12). The absence or mutation of CHL1 can trigger $3 p$ syndrome and schizophrenia (13). The abnormal expression of CHL1 may lead to reduced working memory and social behavior, mental damage, and abnormal behavior (14). CHL1 has been reported to be involved in carcinogenesis and progression in a variety of human cancers. In esophageal squamous cell carcinoma (ESCC), CHL1 downregulation is associated with invasion, lymph node metastasis and poor overall survival (11). Functional studies revealed that CHL1 has anti-proliferation and anti-metastasis abilities (11). The expression of CHL1 is downregulated by hypermethylation in human breast cancer, and its negative expression contributes to breast tumorigenesis and progression $(15,16)$. In thyroid cancer (17) and colonic adenocarcinoma (18), CHL1 impedes cell proliferation and invasion, and acts as a tumor suppressor. In lung cancer, Hötzel et al (19) evaluated CHL1 expression 
in 2,161 NSCLC cases based on a tissue microarray, and it was reported that $\mathrm{CHL} 1$ expression is associated with $\mathrm{T}$ stage in adenocarcinomas, as well as with metastatic lymph node status and improved survival. Additionally, by analyzing the Gene Expression Omnibus dataset GSE21656 submitted by Sun et al (20), microarray results demonstrated that CHL1 expression in DDP-resistant H460 cells is significantly lower compared with that in parental cells, suggesting that CHL1 may be involved in NSCLC chemoresistance; however, to the best of our knowledge, the underlying mechanism remains unknown.

In the present study, the expression of CHL1 in DDP- and PTX-resistant A549 cells and the parental cells was assessed. Functional studies of CHL1 were performed to investigate its potential role in chemoresistance.

\section{Materials and methods}

Data processing. The human GSE21656 microarray dataset (20) was downloaded from the NCBI Gene Expression Omnibus (GEO) database (www.ncbi.nlm.nih.gov/geo). The available dataset, GSE21656 was based on the GPL6244 platform (Affymetrix Human Gene 1.0 ST Array, Affymetrix; Thermo Fisher Scientific, Inc.). This data includes H460 cells and DDP-resistant H460 cells sample, and each cell has three repeats samples. The online tool, GEO2R (http://www.ncbi. nlm.nih.gov/geo/geo2r) (21) was used to determine the differentially expressed genes in H460 and DDP-resistant H460 cells. $\mathrm{P}<0.05$ and $\log _{2}$ fold-changel $\geq 1$ were set as cut-off standards.

Cell culture. The human NSCLC cell line A549, the PTX-resistant cell line A549/PTX and the DDP-resistant cells A549/DDP were purchased from Procell Life Science \& Technology Co., Ltd. The cells were cultured in Ham's F-12K medium supplemented with $10 \%$ fetal bovine serum (both purchased from Thermo Fisher Scientific, Inc.), $100 \mathrm{U} / \mathrm{ml}$ penicillin and $100 \mathrm{U} / \mathrm{ml}$ streptomycin (cat. no. 15140122; Thermo Fisher Scientific, Inc.), in a $37^{\circ} \mathrm{C}$ humidified incubator with $5 \% \mathrm{CO}_{2}$.

Cell transfection. The resistant cells A549/PTX and A549/DDP cells were transfected with $4.0 \mu \mathrm{g}$ CHL1 recombinant expression plasmid (cat. no. HG10143-NY; Sino Biological, Inc.). Empty vector (pCMV3-SP-N-HA) was used as the control. A549 cells were transfected with 100 pmol small interfering (si)RNAs. The siRNA sequence for CHL1 (Guangzhou RiboBio Co., Ltd.) were siRNA-1, 5'-GGAGCUAAUUUG ACCAUAUtt-3', siRNA-2, 5'-CAGCAAUAUUAGCGAGUA Utt-3' and scrambled control, 5'-UUCUCCGAACGUGUC ACGUtt-3'. Plasmids and siRNAs were transfected into cells using Lipofectamine ${ }^{\circledR} 2000$ (Thermo Fisher Scientific, Inc.) following the manufacturer's instructions. The time interval between transfection and subsequent experimentation was $48 \mathrm{~h}$. For the rescue experiments, the CHL1 silenced A549 cells were treated with the Akt inhibitor SC66 (cat. no. S5313; Selleck Chemicals), along with DDP $(1.5 \mu \mathrm{g} / \mathrm{ml})$ or PTX $(35 \mathrm{ng} / \mathrm{ml}$; both purchased from Selleck Chemicals) for $24 \mathrm{~h}$ at $37^{\circ} \mathrm{C}$.

$R N A$ extraction and reverse transcription-quantitative $P C R$ $(R T-q P C R)$ assay. Total RNAs were isolated using TRIzol reagent (Thermo Fisher Scientific, Inc.) according to the manufacturer's instructions, and the mixed DNAs were eliminated by DNase I (New England Biolabs, Inc.). First-strand cDNA synthesis was conducted using the GoScriptTM kit (Promega Corporation) according to the manufacturer's instructions. The reaction conditions for reverse transcription were $25^{\circ} \mathrm{C}$ for $5 \mathrm{~min}, 42^{\circ} \mathrm{C}$ for $60 \mathrm{~min}$ and $70^{\circ} \mathrm{C}$ for $5 \mathrm{~min}$. The SYBR Green Real-Time PCR Master mix (Thermo Fisher Scientific, Inc.) was used to perform RT-qPCR, using a LightCycler480 system (Roche Diagnostics $\mathrm{GmbH}$ ). The CHL1 primer sequences were as follows: Forward, 5'-GGC TTGGTCTCTTGCTTTCC-3' and reverse, 5'-ATCTTCCCT CCCTTTGCACG-3'; and $\beta$-actin forward, 5'-TTCCTTCCT GGGCATGGAGTC-3' and reverse, 5'-TCTTCATTGTGC TGGGTGCC-3'. The following thermocycling conditions were used for qPCR: $1 \mathrm{~min}$ at $95^{\circ} \mathrm{C}$, followed by 40 cycles at $95^{\circ} \mathrm{C}$ for $20 \mathrm{sec}, 30 \mathrm{sec}$ at $60^{\circ} \mathrm{C}$ and a final extension at $72^{\circ} \mathrm{C}$ for $30 \mathrm{sec}$. Each reaction was conducted in triplicate. Relative expression levels were calculated using the $2^{-\Delta \Delta \mathrm{Cq}}$ method (22).

Cell viability. Cell viability was detected by MTT assay. A cell suspension $(100 \mu \mathrm{l})$ was seeded into 96 -well plates at a density of $1 \times 10^{4}$ cells/well and incubated overnight at $37^{\circ} \mathrm{C}$. The concentrations of DDP used to treat A549 cells were $0.5,1,1.5,2$ and $2.5 \mu \mathrm{g} / \mathrm{ml}$. While the concentrations of PTX used to treat A549 cells were 10,20,30,40 and $50 \mathrm{ng} / \mathrm{ml}$. The concentrations of DDP used to treat A549/DDP cells were 2, 4, 6,8 and $10 \mu \mathrm{g} / \mathrm{ml}$. While the concentrations of PTX used to treat A549/PTX cells were 50, 100, 150, 200 and $250 \mathrm{ng} / \mathrm{ml}$. After treating with different concentrations of DDP or PTX for $48 \mathrm{~h}$ at $37^{\circ} \mathrm{C}, 100 \mu \mathrm{l} \mathrm{MTT}(5 \mathrm{mg} / \mathrm{ml})$ solution was added to each well and incubated for $4 \mathrm{~h}$ at $37^{\circ} \mathrm{C}$. Subsequently, $150 \mu \mathrm{l}$ DMSO was added to each well to dissolve the blue formazan crystals and the absorbance was measured using a microplate reader (BioTek Instruments, Inc.) at $570 \mathrm{~nm}$.

Clone formation assay. A total of $1 \times 10^{3}$ cells were seeded into a $35-\mathrm{mm}$ dish (in triplicate) and maintained in $\mathrm{F}-12 \mathrm{~K}$ medium with or without DDP or PTX at $37^{\circ} \mathrm{C}$ for $48 \mathrm{~h}$. A total of 2 weeks later, cells were fixed in $4 \%$ paraformaldehyde for $15 \mathrm{~min}$ at room temperature and stained with $0.01 \%$ crystal violet dye at room temperature for $15 \mathrm{~min}$. The rate of colony formation was calculated using the following equation: (Number of colonies/number of seeded cells) x 100 .

Flow cytometry. Apoptosis was detected using a FITC Annexin V Apoptosis kit (BD Pharmingen; BD Biosciences) according to the manufacturer's protocol. Cells $\left(1 \times 10^{5}\right)$ were collected and washed twice with PBS prior to being suspended in $500 \mu \mathrm{l}$ binding buffer. Subsequently, cells were incubated with $5 \mu \mathrm{l}$ Annexin V-FITC and $5 \mu \mathrm{l}$ propidium iodide in the dark for $10 \mathrm{~min}$ at room temperature and apoptosis was analyzed using a CytoFlex flow cytometer (Beckman Coulter, Inc.). Data were analyzed using CytEXpert 2.0 software (Beckman Coulter, Inc.). The ratio between early and late apoptosis was calculated.

Western blotting. Cells were collected, washed twice with PBS and lysed with RIPA lysis buffer (Thermo Fisher Scientific, Inc.). Proteins were isolated from the cell lysis buffer and 
quantified using the Piercetm ${ }^{\mathrm{TM}}$ BCA Protein Assay kit (cat. no. 23227; Thermo Fisher Scientific, Inc.) with bovine serum album as a standard. Equal amount of protein $(30 \mu \mathrm{g})$ proteins were separated by $10 \%$ SDS-PAGE gel. Next, the proteins were transferred onto a polyvinylidene membrane (Thermo Fisher Scientific, Inc.), blocked with 5\% BSA (Thermo Fisher Scientific, Inc.) for $2 \mathrm{~h}$ at $4^{\circ} \mathrm{C}$, and incubated overnight at $4^{\circ} \mathrm{C}$ with primary antibodies against CHL1 (1:500; cat. no. 25250-1-AP; ProteinTech, Inc.), multi-drug resistance gene 1 (MDR1; 1:500; cat. no. 22336-1-AP; ProteinTech, Inc.), multidrug resistance-associated protein (MRP; 1:500; cat. no. 67228-1-Ig; ProteinTech, Inc.), low-density lipoprotein receptor-related protein (LRP; 1:500; cat. no. 22336-1-AP; ProteinTech, Inc.), phosphorylated (p)-Akt (1:1,000; cat. no. ab38449; Abcam,) and Akt (1:2,000; cat. no. ab227385; Abcam). After washing three times with PBS, the membrane was incubated with horseradish peroxide-conjugated goat anti-rabbit $(1: 2,000$; cat. no. ab6271; Abcam)_or rabbit anti-mouse (1:2,000; cat. no. ab6728; Abcam) secondary antibodies for $2 \mathrm{~h}$ at room temperature and the blots were detected with enhanced chemiluminescence reagent (Thermo Fisher Scientific, Inc.). Protein expression was quantified using Image-pro plus 6.0 software (Media Cybernetics, Inc.).

Animal experiments. The animal experiments were approved by the Medical Ethics Committee of Xiangya Changde Hospital (approval no. 20190325) and were performed in compliance with all regulatory institutional guidelines for animal welfare (the National Institutes of Health Publications no. 80-23) (23). A total of 12 male BALB/c-nu mice (4-week-old, $20 \pm 5 \mathrm{~g}$; Hunan SJA Laboratory Animals Center of the Chinese Academy of Sciences) were used in this study. All animals were kept at the SPF level laboratory at $20-25^{\circ} \mathrm{C}$, a relative humidity of $30-70 \%$, a $12 / 12 \mathrm{~h}$ light/dark cycle and 10 times/h of fresh air exchange. All mice were given free access to food and water. The bedding materials, drinking water, feeding cages and other items in contact with the animals were all autoclaved prior to use. A549/DDP cells $\left(1 \times 10^{7}\right)$ transfected with empty vector and CHL1 overexpression vector, using Lipofectamine ${ }^{\circledR}$ 2000 reagent (Thermo Fisher Scientific, Inc.), were subcutaneously injected into the nude mice to establish xenograft models, following anaesthesia with $4 \%$ chloral hydrate $(400 \mathrm{mg} / \mathrm{kg})$. Xenografts were allowed to grow to $\sim 100 \mathrm{~mm}^{3}$ over 2 weeks and the mice were randomly divided into four groups ( $n=3 /$ group) as follows: i) vector group (A549/DDP cells transfected with empty vector and treated with $100 \mu \mathrm{l}$ saline solution); ii) vector-DDP group (A549/DDP cells transfected with empty vector and treated with $10 \mathrm{mg} / \mathrm{kg}$ DDP); iii) CHL1 group (A549/DDP cells transfected with CHL1 overexpression vector and treated with $100 \mu \mathrm{l}$ saline solution) and iv) CHL1-DDP group (A549/DDP cells transfected with CHL1 overexpression vector and treated with $10 \mathrm{mg} / \mathrm{kg}$ DDP). DDP was administered by intraperitoneal injection every 3 days for 2 weeks. The mice were observed daily, and the tumors were measured by a vernier caliper every 7 days. The tumor volumes were calculated as length $\mathrm{x}$ width ${ }^{2} / 2$. A total of 5 weeks post-injection, mice were euthanized with $\mathrm{CO}_{2}$ at $30 \%$ volume displacement rate (VDR) per min using a programmable logic controller (Barry-Wehmiller Design Group, Inc.). Mice were monitored continuously and once the mice were immobile (except for breathing) for $1 \mathrm{~min}$, the VDR was provided at $100 \%$ for $2 \mathrm{~min}$. The animals remained in the euthanasia chamber for $5 \mathrm{~min}$ and were then observed for an additional $5 \mathrm{~min}$. Breathing and heart rate were monitored to determine death.

Statistical analysis. All experiments were performed in triplicate and data are presented as the mean \pm standard deviation. All experiments were performed at least three times. Paired Student's t-test was performed for comparisons between two groups and one-way analysis of variance followed by Tukey's multiple comparison post-hoc analysis was performed for comparisons between multiple groups. SPSS 20.0 (IBM Corp.) was used to perform the analysis. $\mathrm{P}<0.05$ was considered to indicate a statistically significant difference.

\section{Results}

CHL1 is downregulated in A549/DDPandA549/PTX-resistant cells. In order to investigate the mechanism of chemoresistance in lung cancer, the lung adenocarcinoma cell line A549, the DDP-resistant cells (A549/DDP) and PTX-resistant cells (A549/PTX) were used in the present study. Cells were exposed to different concentrations of DDP $(0-8 \mu \mathrm{g} / \mathrm{ml})$ and PTX $(0-160 \mathrm{ng} / \mathrm{ml})$, and MTT assay was used to detect the cell survival rate. A549/DDP and A549/PTX cells demonstrated higher resistance to DDP and PTX compared with A549 cells (Fig. 1A). The half maximal inhibitory concentration $\left(\mathrm{IC}_{50}\right)$ of DDP was significantly higher in A549/DDP cells $(8.30 \pm 0.92 \mu \mathrm{g} / \mathrm{ml})$ compared with A549 cells $(1.68 \pm 0.18 \mu \mathrm{g} / \mathrm{ml})$, and the $\mathrm{IC}_{50}$ of PTX was significantly higher in A549/PTX cells $(174.80 \pm 8.64 \mathrm{ng} / \mathrm{ml})$ compared with A549 cells $(36.97 \pm 2.56 \mathrm{ng} / \mathrm{ml}$; Fig. 1B). In addition, the expression levels of the drug-resistant markers MDR1, MRP and LRP were significantly higher in A549/DDP and A549/PTX cells compared with A549 cells (Fig. 1C). Additionally, the mRNA and protein expression levels of CHL1 were significantly lower in A549/DDP and A549/PTX cells compared with those in A549 cells (Fig. 1D and E), and this was also observed in H460 DDP-resistant cells obtained from the GEO dataset (GSE21656; Fig. 1F). These results suggested that CHL1 may be involved in regulating DDP and PTX resistance in NSCLC.

Knockdown of CHL1 enhances resistance to DDP and PTX in A549 cells. As CHL1 was upregulated in A549 cells, CHL1 was silenced in A549 cells using siRNAs. CHL1 expression was significantly reduced in the CHL1 siRNA groups compared with that of the scrambled control group (Fig. 2A). As siRNA-1 demonstrated the greatest interference efficiency, it was selected for use in the following experiments. Notably, CHL1-knockdown enhanced the resistance to DDP and PTX in A549 cells (Fig. 2B and C). Colony formation assay revealed that compared with the control group, CHL1-knockdown significantly increased the rate of colony formation in the absence of chemotherapeutics and enhanced the resistance to DDP and PTX (Fig. 2D). Flow cytometry results demonstrated significantly reduced apoptosis in CHL1-knockdown cells after DDP and PTX treatment compared with that of the control group (Fig. 2E). 

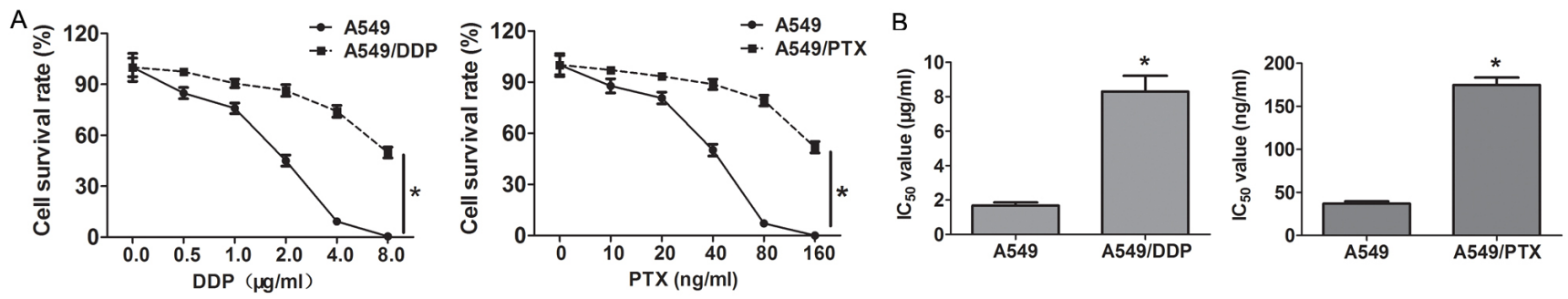

C
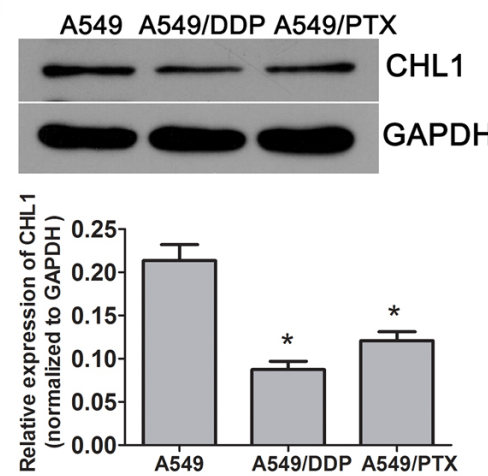

E

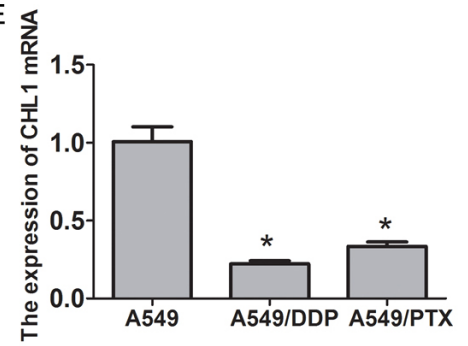

D
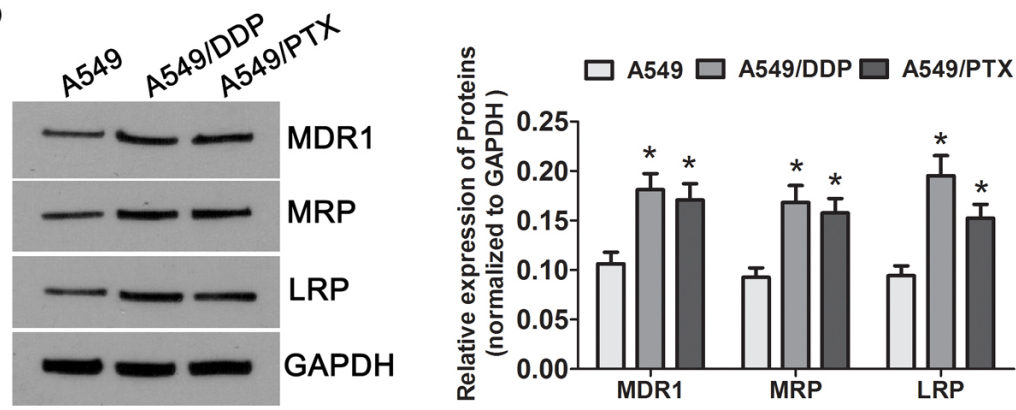

$\mathrm{F}$

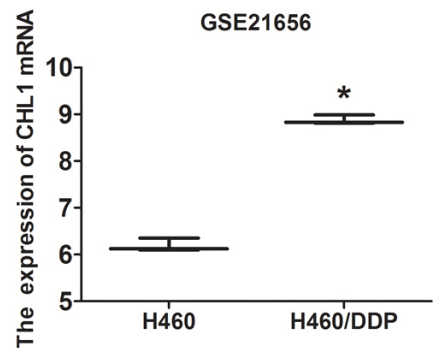

Figure 1. CHL1 is downregulated in DDP and PTX-resistant A549 cells. (A) Cell survival of A549 and A549-resistant cells (A549/DDP and A549/PTX) treated with increasing concentrations of DDP and PTX, as assessed by MTT assay. (B) The $\mathrm{IC}_{50}$ values of DDP in A549/DDP and A549 cells, and the IC 50 values of PTX in A549/PTX and A549 cells. "P<0.05 vs. A549 cells. (C) Western blotting demonstrated the expression of drug resistance-related proteins MDR1, MRP and LRP in A549 cells and A549-resistant cells (A549/DDP and A549/PTX). "P<0.05 vs. A549 cells. The protein and mRNA expression levels of CHL1 in A549 cells and A549-resistant cells (A549/DDP and A549/PTX) were analysed by (D) western blotting and (E) reverse transcription-quantitative PCR, respectively. ${ }^{*} \mathrm{P}<0.05$ vs. A549 cells. (F) The mRNA expression of CHL1 in H460 and H460/DDP cells in the GSE21656 dataset. ${ }^{*} \mathrm{P}<0.05$ vs. H460 cells. CHL1, close homolog of L1; DDP, cisplatin; PTX, paclitaxel; MDR1, multi-drug resistance gene 1; MRP, multidrug resistance-associated protein; LRP, low-density lipoprotein receptor-related protein; IC50, half maximal inhibitory concentration.

CHL1 overexpression enhances the sensitivity of A549 resistant cells to DDP and PTX. As CHL1 is downregulated in A549/DDP and A549/PTX cells, the present study successfully overexpressed CHL1 in these cells using CHL1 recombinant expression plasmids (Fig. 3A). The results demonstrated that CHL1 overexpression alleviated the resistance to DDP and PTX compared with that of the control group (Fig. 3B and C). In addition, CHL1 overexpression inhibited colony formation in the absence or presence of DDP and PTX (Fig. 3D). Additionally, flow cytometry results demonstrated that restoration of CHL1 expression promoted apoptosis in resistant cells following DDP and PTX treatment (Fig. 3E).

To further validate the effects of CHL1 overexpression on DDP or PTX sensitivity, xenograft mice model experiments were performed. The results demonstrated that CHL1 overexpression or DDP treatment significantly impeded the tumor growth (Fig. 3F) and decreased the tumor weight (Fig. 3G). In addition, CHL1 overexpression further aggravated DDP-mediated repression on tumor growth (Fig. 3F and G). These data suggested that CHL1 overexpression suppressed tumor growth and enhanced the chemosensitivity in NSCLC.

CHL1 mediates chemosensitivity by inhibiting Akt activity. Recently, studies have confirmed that CHL1 inhibits Akt activity in ESCC and neuroblastoma cell lines $(11,24)$. Thus, the present study investigated whether CHL1 mediates chemoresistance via the Akt pathway in NSCLC. In A549 cells, compared with the scrambled group, CHL1-knockdown elevated the expression of p-Akt ${ }^{\mathrm{ser} 473}$ (Fig. 4A). By contrast, restoring CHL1 expression in A549/DDP and A549/PTX cells inhibited the Akt phosphorylation compared with the control group (Fig. 4A), suggesting CHL1 mediates chemosensitivity via the Akt pathway. Subsequently, CHL1-silenced A549 cells were treated with the Akt inhibitor SC66, and it was demonstrated that inhibiting Akt activity significantly reduced the promotive effects on cell survival (Fig. 4B) and clone formation (Fig. 4C), and the inhibitory effects on apoptosis (Fig. 4D) induced by CHL1-depletion. These results confirmed that CHL1 mediates chemosensitivity in NSCLC by inhibiting the Akt pathway. 


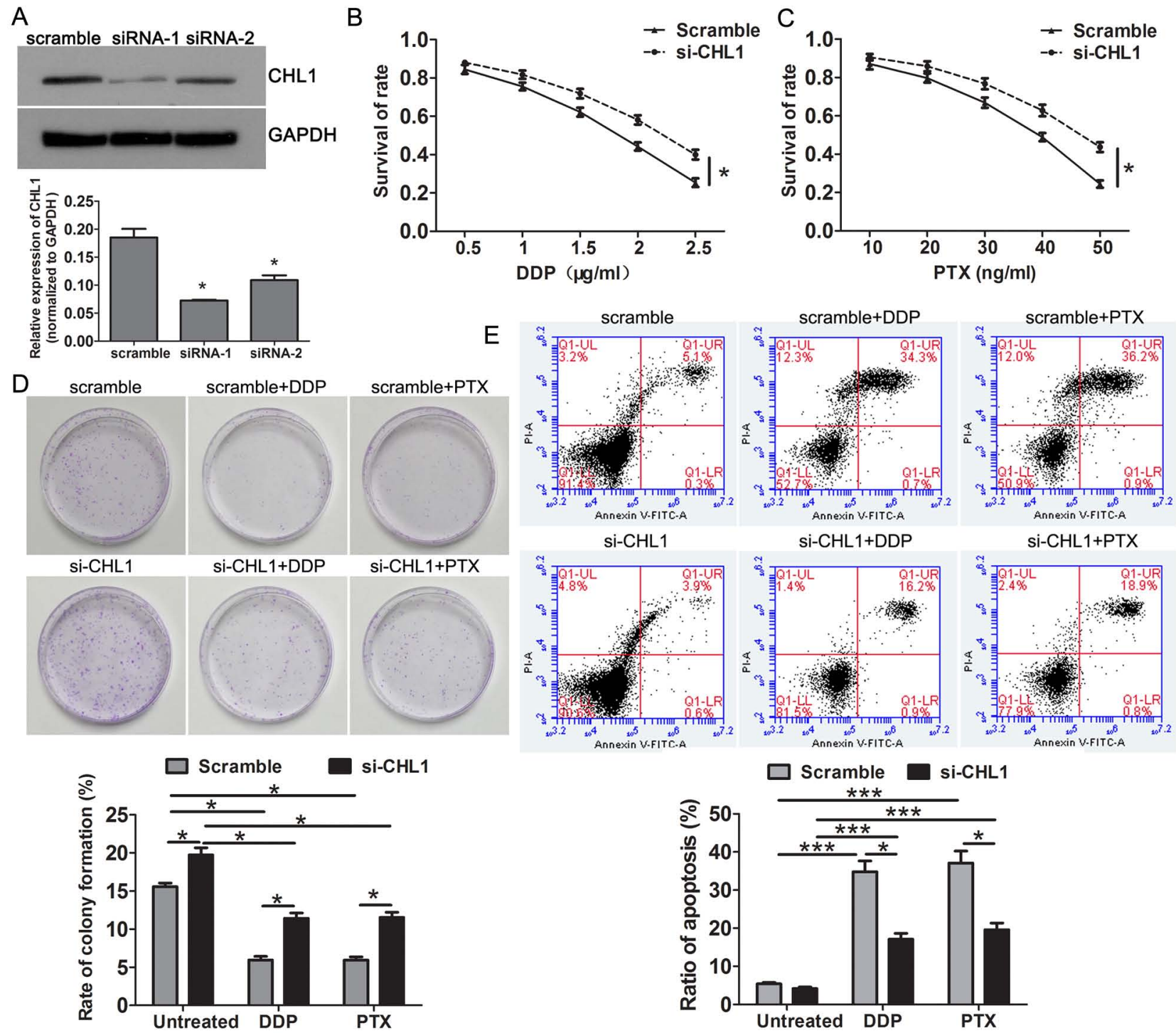

Figure 2. CHL1-knockdown increases A549 cell resistance to DDP and PTX. (A) Western blotting was performed to validate the efficiency of transfection with CHL1 siRNAs. " $\mathrm{P}<0.05$ vs. scramble. MTT assays were performed to determine the survival rate of CHL1-knockdown A549 cells treated with (B) $0-2.5 \mu \mathrm{g} / \mathrm{ml}$ DDP or (C) $0-50 \mathrm{ng} / \mathrm{ml}$ DDP. (D) Colony formation assay of A549 cells transfected with CHL1 siRNA in the presence or absence of $1.5 \mu \mathrm{g} / \mathrm{ml} \mathrm{DDP}$ or $35 \mathrm{ng} / \mathrm{ml}$ PTX. (E) Flow cytometry analysis was used to detect apoptosis in A549 cells transfected with CHL1 siRNA in the presence or absence of $1.5 \mu \mathrm{g} / \mathrm{ml}$ DDP or $35 \mathrm{ng} / \mathrm{ml}$ PTX. ${ }^{*} \mathrm{P}<0.05,{ }^{* * *} \mathrm{P}<0.001$. CHL1, close homolog of L1; DDP, cisplatin; PTX, paclitaxel; si, small interfering.

\section{Discussion}

The results of the present study demonstrated that CHL1 was significantly downregulated in A549/DDP and A549/PTX cells compared with A549 cells. The knockdown of CHL1 in A549 cells facilitated the cell survival and clone formation, and decreased apoptosis when treated with or without DDP and PTX; whereas CHL1 overexpression in A549/DDP and A549/PTX cells inhibited cell survival and clone formation, and increased apoptosis. The results of the present study also demonstrated that CHL1 enhances NSCLC chemosensitivity through inhibition of the Akt pathway. These data suggested that CHL1 may be a promising target to improve the efficacy of chemosensitivity in NSCLC.

CHL1 belongs to the L1 family of nerve cell adhesion molecules, it was initially cloned in mice, and its expression in mouse development was analyzed by Senchenko et al (25). Through cell-cell interactions and mediating cell-cell and cell-matrix interactions, CHL1 has an important effect on the development, regeneration and plasticity of the nervous system (12). Previous reports have demonstrated that CHL1 also participates in carcinogenesis (11,15-18). CHL1 was observed to be significantly downregulated in up to 11 types of tumor tissues compared with their adjacent normal tissues (25). In most tumors, CHL1 is a potential tumor suppressor gene whose silencing is associated with tumor growth, invasion and metastasis (11,15-18). For example, knockdown of CHL1 expression results in enhanced cervical cancer cell invasion and migration $(26,27)$. A low expression of CHL1 in patients with neuroblastoma predicts a poor prognosis, and enhancing CHL1 expression suppresses tumor progression (24). In contrast, CHL1 has been reported to promote cell proliferation, metastasis and migration in human gliomas (28). However, to the best of our knowledge research on CHL1 and tumor chemoresistance has rarely been reported. 

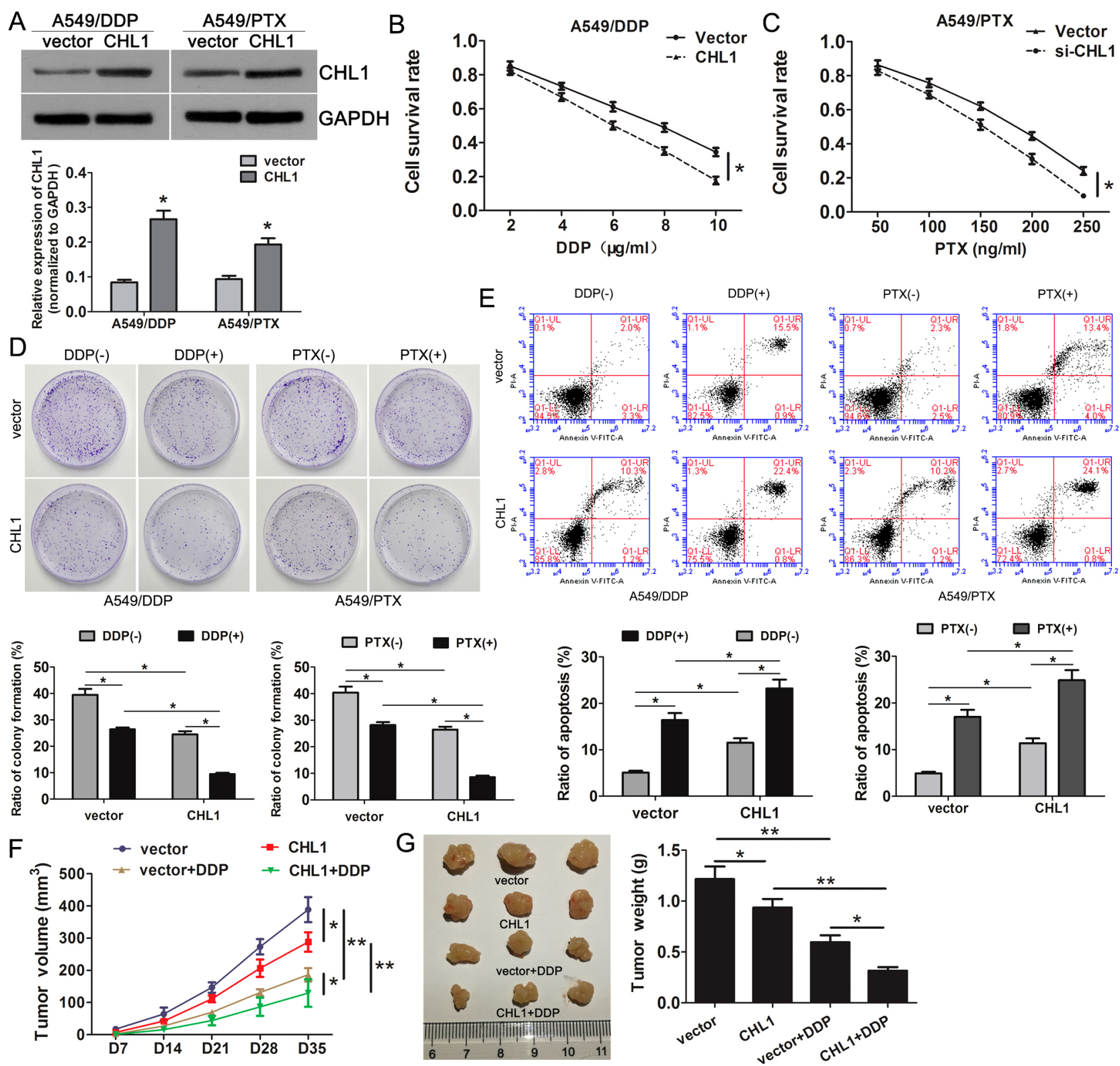

Figure 3. Overexpression of CHL1 increases the sensitivity of resistant A549 cells to DDP and PTX. (A) Western blotting was performed to detect CHL1 expression in A549/DDP and A549/PTX cells transfected with CHL1 expression plasmids. "P $<0.05$ vs. vector. Effect of CHL1 overexpression on resistant A549 cell survival rate when treated with (B) $0-10 \mu \mathrm{g} / \mathrm{ml}$ DDP or (C) $0-250 \mathrm{ng} / \mathrm{ml} \mathrm{PTX}$, as determined by MTT assay. (D) Colony formation assays demonstrated the number of colonies of resistant A549 cells transfected with CHL1 expression plasmids in the presence or absence of $8 \mu \mathrm{g} / \mathrm{ml} \mathrm{DDP} \mathrm{or} 160 \mathrm{ng} / \mathrm{ml}$ PTX. (E) Flow cytometry analysis was performed to assess apoptosis in resistant A549 cells transfected with CHL1 expression plasmids in the presence or absence of $8 \mu \mathrm{g} / \mathrm{ml}$ DDP or $160 \mathrm{ng} / \mathrm{ml}$ PTX. CHL1 overexpression enhanced chemosensitivity of A549/DDP cells to DDP in vivo, which was demonstrated by the effect of DDP treatment or CHL1 overexpression on the (F) growth and (G) weight of xenografts derived from A549/DDP cells. ${ }^{*} \mathrm{P}<0.05$, ${ }^{* *} \mathrm{P}<0.01$. CHL1, close homolog of L1; DDP, cisplatin; PTX, paclitaxel.

The present study examined the differentially expressed genes in NSCLC DDP-resistant cells in a GEO dataset. CHL1 was demonstrated to be upregulated in DDP-resistant cells compared with parental cells, suggesting that CHL1 may be involved in NSCLC chemotherapy resistance. Similarly, a study that compared and analyzed the differentially expressed genes in chemosensitive tumors and chemoresistant ovarian adenocarcinomas tissues reported that the expression of CHL1 in chemotherapy-sensitive tumor tissues is higher compared with that in drug-resistant tissues, suggesting that CHL1 may help to predict the efficacy of chemotherapy for ovarian cancer (29). In addition, aberrant methylation of CHL1 may be associated with the recurrence of colorectal cancer (CRC) following chemotherapy. 5-azadC treatment restores 5-flurouracil sensitivity in vitro, which also suggests that CHL1 may be involved in CRC chemotherapy resistance (30). The results of the present study demonstrated that CHL1 was downregulated in A549/DDP cells. Additionally, as multiple drug resistance is a common characteristic, another type of resistant cells (A549/TAX cells) were also used in the current study. The results also demonstrated that CHL1 was downregulated in A549/PTX cells. Compared with control cells, overexpression of CHL1 significantly increased the sensitivity of cells resistant to DDP and PTX, whereas knockdown of CHL1 expression in 

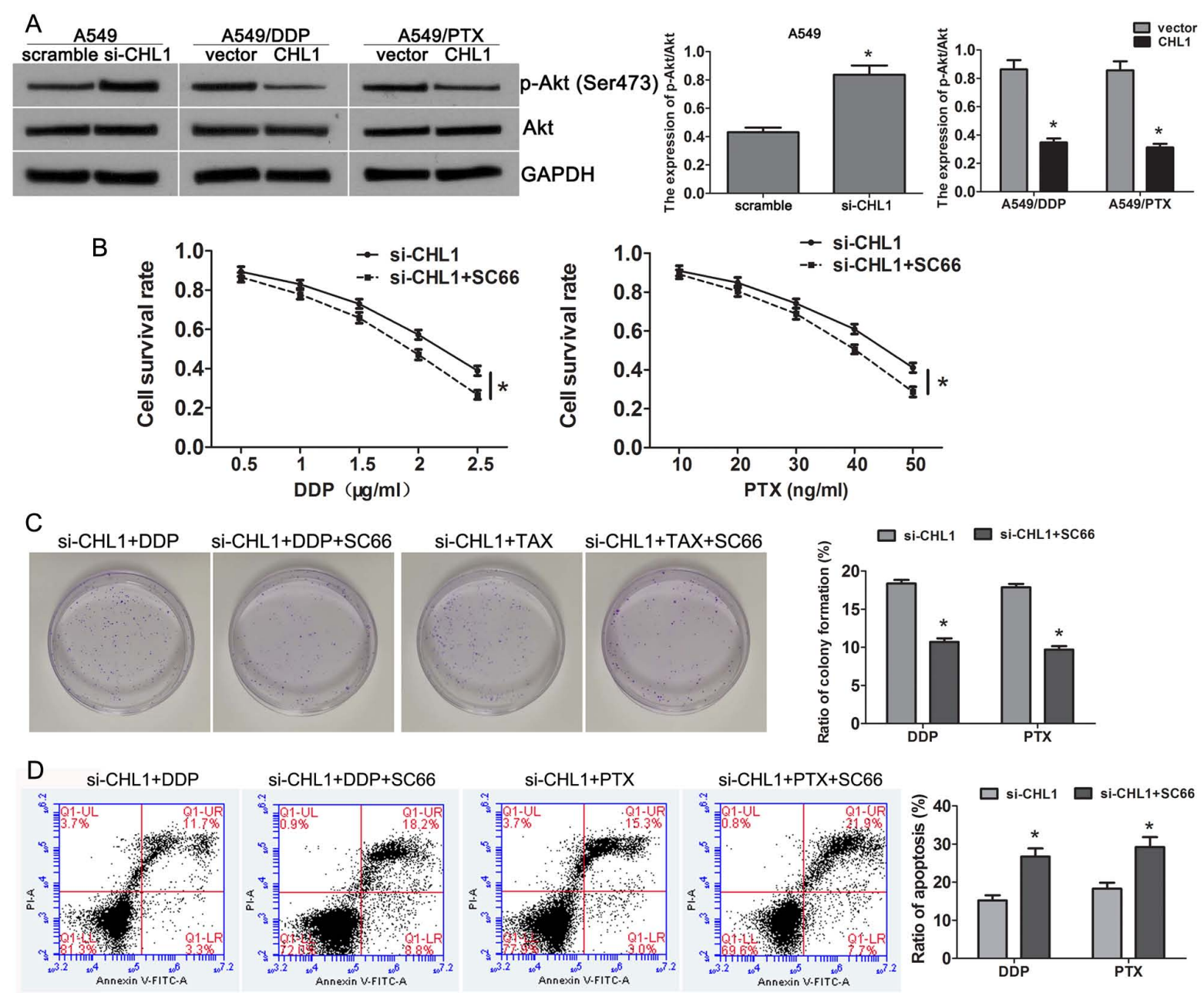

Figure 4. CHL1 mediates DDP and PTX sensitivity by inhibiting Akt activity. (A) Western blotting was performed to detect the expression of p-Akt and total Akt in CHL-silenced and -restored cell models. "P $<0.05$ vs. scramble or vector. (B) MTT assays were performed to detect cell survival rates of A549 cells treated with CHL1 siRNA and Akt inhibitor SC66. ${ }^{*} \mathrm{P}<0.05$. (C) Colony formation assays were performed in A549 cells treated with CHL1 siRNA and the Akt inhibitor SC66 in the presence of DDP $(1.5 \mu \mathrm{g} / \mathrm{ml})$ or PTX $(35 \mathrm{ng} / \mathrm{ml})$. ${ }^{*} \mathrm{P}<0.05 \mathrm{vs}$. si-CHL1. (D) Apoptosis were measured in A549 cells treated with CHL1 siRNA and Akt inhibitor SC66 in the presence of DDP $(1.5 \mu \mathrm{g} / \mathrm{ml})$ and PTX (35 ng/ml). "P<0.05 vs. si-CHL1. CHL1, close homolog of L1; DDP, cisplatin; PTX, paclitaxel; si, small interfering; p-, phosphorylated.

parent A549 cells displayed the opposite results. To the best of our knowledge, this study is the first study to suggest that CHL1 may be involved in chemosensitivity in lung cancer. The concentration of DDP used in vivo is $10 \mathrm{mg} / \mathrm{kg}(8,31)$, however, this may not be in line with the concentrations that would be used in a clinical setting. In a clinical trial, the human initial dose was calculated from the no observed adverse effect levels (NOAELs) verified in animal experiments. NOAEL is the maximum dose level without significant adverse reactions. The NOAEL verified in animal experiments can be converted to a human equivalent dose according to the body surface area conversion, which is based on the area standardization $\left(\mathrm{mg} / \mathrm{m}^{2}\right)$ proportional among different species (32). In the present study, the concentration of DDP used in vivo was not the NOAEL, thus it was not consistent with the concentrations used in clinical settings.

Akt is a serine/threonine protein kinase that is activated by phosphorylation (33). As a key molecule of the PI3K/Akt signaling pathway, p-Akt regulates cell survival, cell growth, cell motility and angiogenesis, and prevents apoptosis (24).
Additionally, Akt activation is associated with tumor chemoresistance $(33,34)$. The results of the present study demonstrated that compared with the control groups the expression of $\mathrm{p}-\mathrm{Akt}$ was increased in CHL1-knockdown A549 cells, and its expression was reduced in CHL1 overexpressed A549/DDP and A549/PTX cells. When Akt activity was inhibited by the Akt inhibitor, the sensitivity to DDP and PTX in CHL1-knockdown A549 cells was restored. This finding suggested that CHL1 enhanced the chemosensitivity of NSCLC by inhibiting the Akt pathway. Considering numerous studies have confirmed that the Akt pathway mediates chemoresistance via regulation of ATP binding cassette (ABC) members (35-37), the present study didn't further investigate the specific $\mathrm{ABC}$ members and mechanisms, which was a of the limitation to the present study; thus, this research should be further investigated in vivo.

In summary, the present study demonstrated that CHL1 was downregulated in resistant cells A549/DDP and A549/PTX, and upregulation of CHL1 enhanced the chemosensitivity of NSCLC via inhibiting the Akt pathway. To the best of our knowledge, this was the first study to confirm the function and 
mechanism of CHL1 in mediating chemosensitivity in cancer. Thus, the development of CHL1-based therapeutic strategies may improve the efficacy of chemosensitivity in NSCLC.

\section{Acknowledgements}

The authors of the present study would like to thank Mr. Dingliang Li (Xiangya Hospital, Changsha, China) for his guidance and assistance in flow cytometric analysis.

\section{Funding}

No funding was received.

\section{Availability of data and materials}

The datasets used and/or analyzed during the present study are available from the corresponding author upon reasonable request.

\section{Authors' contributions}

$\mathrm{RH}$ conceived and designed the present study. $\mathrm{XC}, \mathrm{BH}, \mathrm{YH}$ and PL performed experiments and collected the data. SL, $\mathrm{ZZ}$ and $\mathrm{ZH}$ analyzed and interpreted the data. ML and $\mathrm{LZ}$ analyzed the data and prepared the figure. XC, ML and $\mathrm{LZ}$ drafted the initial manuscript and revised it for intellectual content. All authors read and approved the final manuscript.

\section{Ethics approval and consent to participate}

The animal experiments were approved by the Medical Ethics Committee of Xiangya Changde Hospital (Changde, China; approval no. 20190325).

\section{Patient consent for publication}

Not applicable.

\section{Competing interests}

The authors declare that they have no competing interests.

\section{References}

1. Parascandola $\mathrm{M}$ and Xiao L: Tobacco and the lung cancer epidemic in China. Transl Lung Cancer Res 8 (Suppl): S21-S30, 2019.

2. Chen W: Cancer statistics: Updated cancer burden in China. Chin J Cancer Res 27: 1, 2015.

3. Oser MG, Niederst MJ, Sequist LV and Engelman JA: Transformation from non-small-cell lung cancer to small-cell lung cancer: Molecular drivers and cells of origin. Lancet Oncol 16: e165-e172, 2015.

4. Thatcher N, Faivre-Finn C, Blackhall F, Anderson $\mathrm{H}$ and Lorigan P: Sequential platinum-based chemotherapy-thoracic radiotherapy in early stage non-small cell lung cancer. Clin Cancer Res 11 (Suppl): S5051-S5056, 2005.

5. Yano T, Okamoto T, Fukuyama S and Maehara Y: Therapeutic strategy for postoperative recurrence in patients with non-small cell lung cancer. World J Clin Oncol 5: 1048-1054, 2014.

6. Fang Z, Chen W, Yuan Z, Liu X and Jiang H: LncRNA-MALAT1 contributes to the cisplatin-resistance of lung cancer by upregulating MRP1 and MDR1 via STAT3 activation. Biomed Pharmacother 101: 536-542, 2018.
7. Cai Y, Dong ZY and Wang JY: LncRNA NNT-AS1 is a major mediator of cisplatin chemoresistance in non-small cell lung cancer through MAPK/Slug pathway. Eur Rev Med Pharmacol Sci 22: 4879-4887, 2018.

8. Han ML, Zhao YF, Tan CH, Xiong YJ, Wang WJ, Wu F, Fei Y, Wang L and Liang ZQ: Cathepsin L upregulation-induced EMT phenotype is associated with the acquisition of cisplatin or paclitaxel resistance in A549 cells. Acta Pharmacol Sin 37: 1606-1622, 2016

9. Liu J, Meisner D, Kwong E, Wu XY and Johnston MR: Translymphatic chemotherapy by intrapleural placement of gelatin sponge containing biodegradable Paclitaxel colloids controls lymphatic metastasis in lung cancer. Cancer Res 69: 1174-1181, 2009.

10. Hassan WA, Yoshida R, Kudoh S, Kameyama H, Hasegawa K, Niimori-Kita K and Ito T: Notch1 controls cell chemoresistance in small cell lung carcinoma cells. Thorac Cancer 7: 123-128, 2016.

11. Tang H, Jiang L, Zhu C, Liu R, Wu Y, Yan Q, Liu M, Jia Y, Chen J, Qin Y, et al: Loss of cell adhesion molecule L1 like promotes tumor growth and metastasis in esophageal squamous cell carcinoma. Oncogene 38: 3119-3133, 2019.

12. Liu H, Focia PJ and He X: Homophilic adhesion mechanism of neurofascin, a member of the L1 family of neural cell adhesion molecules. J Biol Chem 286: 797-805, 2011.

13. Tassano E, Biancheri R, Denegri L, Porta S, Novara F, Zuffardi O, Gimelli G and Cuoco C: Heterozygous deletion of CHL1 gene: Detailed array-CGH and clinical characterization of a new case and review of the literature. Eur J Med Genet 57: 626-629, 2014.

14. Morellini F, Lepsveridze E, Kahler B, Dityatev A and Schachner M: Reduced reactivity to novelty, impaired social behavior, and enhanced basal synaptic excitatory activity in perforant path projections to the dentate gyrus in young adult mice deficient in the neural cell adhesion molecule CHL1. Mol Cell Neurosci 34: 121-136, 2007.

15. He LH, Ma Q, Shi YH, Ge J, Zhao HM, Li SF and Tong ZS: CHL1 is involved in human breast tumorigenesis and progression. Biochem Biophys Res Commun 438: 433-438, 2013.

16. Martín-Sánchez E, Mendaza S, Ulazia-Garmendia A, Monreal-Santesteban I, Blanco-Luquin I, Córdoba A, Vicente-García F, Pérez-Janices N, Escors D, Megías D, et al: CHL1 hypermethylation as a potential biomarker of poor prognosis in breast cancer. Oncotarget 8: 15789-15801, 2017.

17. Zhu H, Fang J, Zhang J, Zhao Z, Liu L, Wang J, Xi Q and $\mathrm{Gu} \mathrm{M}$ : miR-182 targets CHL1 and controls tumor growth and invasion in papillary thyroid carcinoma. Biochem Biophys Res Commun 450: 857-862, 2014.

18. Yu W, Zhu K, Wang Y, Yu H and Guo J: Overexpression of miR-21-5p promotes proliferation and invasion of colon adenocarcinoma cells through targeting CHL1. Mol Med 24: 36, 2018.

19. Hötzel J, Melling N, Müller J, Polonski A, Wolters-Eisfeld G, Izbicki JR, Karstens KF and Tachezy M: Protein expression of close homologue of L1 (CHL1) is a marker for overall survival in non-small cell lung cancer (NSCLC). J Cancer Res Clin Oncol 145: 2285-2292, 2019.

20. Sun Y, Zheng S, Torossian A, Speirs CK, Schleicher S, Giacalone NJ, Carbone DP, Zhao Z and Lu B: Role of insulin-like growth factor-1 signaling pathway in cisplatin-resistant lung cancer cells. Int J Radiat Oncol Biol Phys 82: e563-e572, 2012.

21. Barrett T, Wilhite SE, Ledoux P, Evangelista C, Kim IF, Tomashevsky M, Marshall KA, Phillippy KH, Sherman PM, Holko M, et al: NCBI GEO: Archive for functional genomics data sets-update. Nucleic Acids Res 41 (Database issue): D991-D995, 2013.

22. Livak KJ and Schmittgen TD: Analysis of relative gene expression data using real-time quantitative PCR and the 2(-Delta Delta $\mathrm{C}(\mathrm{T})$ ) method. Methods 25: 402-408, 2001.

23. Chen Y, Wang H, Xiong T, Zou R, Tang Z and Wang J: The role of LASS2 in regulating bladder cancer cell tumorigenicity in a nude mouse model. Oncol Lett 14: 5149-5156, 2017.

24. Ognibene M, Pagnan G, Marimpietri D, Cangelosi D, Cilli M, Benedetti MC, Boldrini R, Garaventa A, Frassoni F, Eva A, et al: CHL1 gene acts as a tumor suppressor in human neuroblastoma. Oncotarget 9: 25903-25921, 2018.

25. Senchenko VN, Krasnov GS, Dmitriev AA, Kudryavtseva AV, Anedchenko EA, Braga EA, Pronina IV, Kondratieva TT, Ivanov SV, Zabarovsky ER and Lerman MI: Differential expression of CHL1 gene during development of major human cancers. PLoS One 6: e15612, 2011.

26. Chu Y, Ouyang Y, Wang F, Zheng A, Bai L, Han L, Chen Y and Wang H: MicroRNA-590 promotes cervical cancer cell growth and invasion by targeting CHL1. J Cell Biochem 115: 847-853, 2014. 
27. Long MJ, Wu FX, Li P, Liu M, Li X and Tang H: MicroRNA-10a targets CHL1 and promotes cell growth, migration and invasion in human cervical cancer cells. Cancer Lett 324: 186-196, 2012.

28. Yang Z, Xie Q, Hu CL, Jiang Q, Shen HF, Schachner M and Zhao WJ: CHL1 is expressed and functions as a malignancy promoter in glioma cells. Front Mol Neurosci 10: 324, 2017.

29. Choi CH, Choi JJ, Park YA, Lee YY, Song SY, Sung CO, Song T, Kim MK, Kim TJ, Lee JW, et al: Identification of differentially expressed genes according to chemosensitivity in advanced ovarian serous adenocarcinomas: Expression of GRIA2 predicts better survival. Br J Cancer 107: 91-99, 2012.

30. Baharudin R, Ab Mutalib NS, Othman SN, Sagap I, Rose IM, Mohd Mokhtar N and Jamal R: Identification of predictive DNA methylation biomarkers for chemotherapy response in colorectal cancer. Front Pharmacol 8: 47, 2017.

31. Wang CK, Zhang Y, Zhang ZJ, Qiu QW, Cao JG and He ZM: Effects of VBMDMP on the reversal of cisplatin resistance in human lung cancer A549/DDP cells. Oncol Rep 33: 372-382, 2015.

32. Gao Y, Wang Y,Li Y, Han R, Li C, Xiao L, Cho S, Ma Y, Fang C and Lee AW: Repeated sub-chronic oral toxicity study of xylooligosaccharides (XOS) in dogs. Regul Toxicol Pharmacol 86: 379-385, 2017.

33. Wu YH, Huang YF, Chen CC and Chou CY: Akt inhibitor SC66 promotes cell sensitivity to cisplatin in chemoresistant ovarian cancer cells through inhibition of COL11A1 expression. Cell Death Dis 10: 322, 2019.
34. Clark AS, West K, Streicher S and Dennis PA: Constitutive and inducible Akt activity promotes resistance to chemotherapy, trastuzumab, or tamoxifen in breast cancer cells. Mol Cancer Ther 1: 707-717, 2002.

35. Imai Y, Yamagishi H, Ono $\mathrm{Y}$ and Ueda Y: Versatile inhibitory effects of the flavonoid-derived PI3K/Akt inhibitor, LY294002, on ATP-binding cassette transporters that characterize stem cells. Clin Transl Med 1: 24, 2012.

36. Sims JT, Ganguly SS, Bennett H, Friend JW, Tepe J and Plattner R: Imatinib reverses doxorubicin resistance by affecting activation of STAT3-dependent NF-kappaB and HSP27/p38/AKT pathways and by inhibiting ABCB1. PLoS One 8: e55509, 2013.

37. Wang X, He S, Gu Y, Wang Q, Chu X, Jin M, Xu L, Wu Q, Zhou Q, Wang B, et al: Fatty acid receptor GPR120 promotes breast cancer chemoresistance by upregulating $\mathrm{ABC}$ transporters expression and fatty acid synthesis. EBioMedicine 40: 251-262, 2019.

This work is licensed under a Creative Commons Attribution-NonCommercial-NoDerivatives 4.0 International (CC BY-NC-ND 4.0) License. 